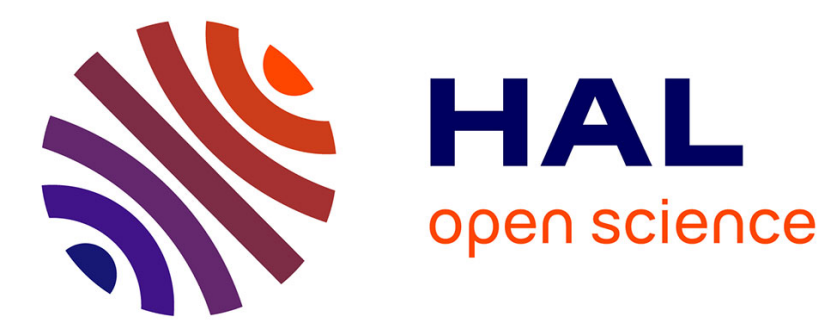

\title{
Permeation and self-diffusion in smectics A
}

O. Parodi

\section{- To cite this version:}

O. Parodi. Permeation and self-diffusion in smectics A. Journal de Physique Lettres, 1976, 37 (6), pp.143-144. 10.1051/jphyslet:01976003706014300 . jpa-00231259

\section{HAL Id: jpa-00231259 https://hal.science/jpa-00231259}

Submitted on 1 Jan 1976

HAL is a multi-disciplinary open access archive for the deposit and dissemination of scientific research documents, whether they are published or not. The documents may come from teaching and research institutions in France or abroad, or from public or private research centers.
L'archive ouverte pluridisciplinaire HAL, est destinée au dépôt et à la diffusion de documents scientifiques de niveau recherche, publiés ou non, émanant des établissements d'enseignement et de recherche français ou étrangers, des laboratoires publics ou privés. 
Classification

Physics Abstracts

7.130

\title{
PERMEATION AND SELF-DIFFUSION IN SMECTICS A
}

\author{
O. PARODI \\ Groupe de Dynamique des Phases Condensées $\left({ }^{*}\right)$, U.S.T.L., \\ Laboratoire de Minéralogie, place Eugène-Bataillon, 34060 Montpellier Cedex, France
}

(Reçu le 27 février 1976, accepté le 15 avril 1976)

\begin{abstract}
Résumé. - Des expériences récentes de R.M.N. et de diffusion quasi-élastique des neutrons dans les smectiques A ont donné des valeurs comparables pour les coefficients de self-diffusion $D_{\|}$(diffusion normale aux couches) et $D_{\perp}$. On montre que la perméation n'intervient pas dans une expérience de self-diffusion et, par suite, que la relation d'Einstein relie $D_{\|}$à une viscosité effective $\eta_{\|}$, et non au coefficient de perméation $\lambda_{\mathrm{p}}$, ce qui explique les résultats expérimentaux.
\end{abstract}

\begin{abstract}
Recent R.M.N. and quasi-elastic neutron scattering experiments on smectics A have given comparable values for the self-diffusion coefficients $D_{\|}$(diffusion normal to the layers) and $D_{\perp}$, in spite of the possible occurence of a permeation process which would lead to much lower values for $D_{\|}$. It is shown that there is no permeation in a self-diffusion experiment, and therefore that the Einstein relation connects $D_{\|}$to an effective viscosity $\eta_{\|}$but not to the permeation coefficient $\lambda_{\mathrm{p}}$, which explains the experimental results.
\end{abstract}

1. Introduction. - Proton magnetic resonance experiments [1] parallel and perpendicular self-diffusion coefficients were measured in smectics A-TBBA and $\operatorname{EBBA}\left(D_{\|}\right.$is related to diffusion parallel to the optical axis, i.e. normal to the layers). It was found that $D_{\|}$and $D_{\perp}$ were of the same order of magnitude. This results are consistent with high resolution neutron quasi-elastic data on TBBA obtained both with a powder [2a] and an aligned sample [2b]. This result seemed surprising, since, taking into account the very small value of the permeation coefficient, one could expect a much smaller value for $D_{\|}$than for $D_{\perp}$, as was pointed out by certain participants to the European Conference on Thermotropic Smectics (Les Arcs, 1975). It will be shown here that, in smectics, $D_{\|}$is related not to permeation but, as in nematics and isotropic fluids, to viscosity.

2. Theoretical approach. - The starting point is classical [3]. From Einstein's relation

$$
D_{\|}=k T \mu_{\|}
$$

where $\mu_{\|}$is a mobility defined by

$$
f_{\|}=\mu_{\|} V_{\|}
$$

$f_{\|}$is the parallel component of the force acting on a diffusing molecule.

In isotropic fluids, one then considers the molecule as a sphere, and applies Stokes' law, which leads to

$$
\mu=(6 \pi \eta a)^{-1}
$$

$\eta$ is the viscosity and $a$ a molecular radius.
In smectics, the problem is a little more complex, since a motion through the layers can involve permeation. It is therefore useful to turn back to the definition of permeation $[4,5]$ as the relative motion of the fluid and of the layers.

Consider a self-diffusion experiment performed on a smectic $A$ in a planar configuration. Some of the molecules are marked and the system is prepared in such a way that at time $t=0$, a concentration gradient along the $Z$-direction (normal to the layers) $\partial C / \partial Z$ is imposed. Then the marked molecules diffuse according to

$$
\dot{C}=-D_{\|} \frac{\partial^{2} C}{\partial Z^{2}} .
$$

Their flow is balanced by a back-flow of non-marked molecules such that the total fluid-velocity, $v_{z}$, vanishes.

The equations of motion for a smectic in a quasiplanar configuration (with only small distortions of the planar structures) are [4]

$$
\begin{gathered}
\dot{u}=v_{z}+\lambda_{\mathrm{p}} g . \\
\rho \dot{v}_{z}=-\frac{\partial p}{\partial Z}+g+(\boldsymbol{\eta}: \nabla \nabla) v_{z}
\end{gathered}
$$

where :

$u$ is the layer displacement,

$g$ is the restoring force acting on the layers and $\boldsymbol{\eta}$ is the viscous tensor : for a pure shear flow

$$
v_{z}=v_{z}(x), \quad \boldsymbol{\eta}: \nabla \nabla=\frac{1}{2}\left(\alpha_{4}+\alpha_{56}\right) \frac{\partial^{2}}{\partial x^{2}} .
$$

(*) Laboratoire associé au C.N.R.S. 
Look first at eq. (4). Here $v_{z}$ is given as a function of $\dot{u}$ and $g$, which characterize the layer's dynamics. But the concept of layers has a meaning only at a macroscopic scale, in that sense that their curvature radius must be much larger than a molecular length. This means that, in eq. (4), $\dot{u}$ and $g$ vary very slowly at a microscopic scale, and hence that we cannot take for $v_{z}$ the velocity of a marked molecule but an average over a volume much larger than a molecular volume. In other words, in eq. (4), $v_{z}$ is the fluid velocity, and therefore vanishes. From that, since at time $t=0, g=0$, both $\dot{u}$ and $g$ remain null and the layer configuration is not changed.

Turn back now to eq. (5). In our experiment $p$ is constant, $g$ vanishes, and the only remaining force is the viscous one, which characterizes the dissipation due to molecular collision. Thus eq. (5) keeps a meaning at a molecular scale : $\rho \dot{v}_{z}$ is the force per unit volume. Applying eq. (5) to marked molecules, one finds

$$
f_{z}=\Omega \eta_{\|} \frac{\partial^{2} v_{z}}{\partial x^{2}}
$$

where $\Omega$ is a molecular volume and $\eta_{\|}$an effective viscosity

$$
\eta_{\|}=\frac{1}{2}\left(\alpha_{4}+\alpha_{5}\right) .
$$

A crude calculation, for rods of length $a$ and diameter $b$, gives

$$
\Omega \simeq a b^{2}, \quad \frac{\partial^{2} v_{z}}{\partial x^{2}} \simeq v_{z} / b^{2}
$$

and finally

$$
f_{z}=v \eta_{\|} a v_{z}
$$

where $v$ is a numerical coefficient of order one.

Using now eqs. (1) and (2) one finds

$$
D_{\|}=\frac{\dot{k} T}{v \eta_{\|} a} \text {. }
$$

3. Discussion. - In this calculation the energy barrier for permeating molecules between adjacent smectic layers (as far as one can speak of permeation for an individual molecule) has not been taken into account. It will now be shown that the presence of this energy barrier does not modify the previous results.

It is well known that the validity of Einstein's relation (1), which is deduced from equilibrium conditions, does not depend on the presence or absence of an energy barrier. As an example, Einstein relation is valid for electrical conduction in semiconductors, where an activation energy is needed for exciting an electron from a bound donor impurity level to the conduction band. On the other hand, the presence of this energy barrier does not result in any new force, since the total free-energy is not changed in the self-diffusion process (the depths of the energy wells are the same for marked and non-marked molecules). In fact the only effect of this energy barrier is to introduce an activation energy term in the temperature dependence of $\mu_{\|}$(and consequently $D_{\|}$) in the smectic A phase.

The fact that the permeation constant $\lambda_{\mathrm{p}}$ is not directly related to $D_{\|}$explains the results obtained by neutron quasi-elastic scattering experiments $[1,2]$. A similar calculation would give

with

$$
D_{\perp}=\frac{k T}{v^{\prime} \eta_{\perp} a}
$$

$$
\eta_{\perp}=\alpha_{4}
$$

The fact that $\alpha_{4}$ and $\alpha_{56}$ do have not the same temperature dependence explains the different slopes found for the plots of $D_{\perp}$ and $D_{\|}$versus temperature.

The numerical coefficients $v$ and $v^{\prime}$ are of the same order, but probably slightly different, and the experiments performed on TBBA suggest that $v \eta_{\|}$and $v^{\prime} \eta_{\perp}$ are of the same order of magnitude in the smectic $A$ temperature range.

A previous evaluation of $D_{\|}$had been made by de Gennes [6] who expected it to be comparable to $B \lambda_{\mathrm{p}}$, where $B$ is the rigidity coefficient of the layers. Keeping in mind that $B \simeq k T / a^{3}$ and $\lambda_{\mathrm{p}} \simeq a^{2} / \eta$, one finds

$$
B \lambda_{\mathrm{p}} \simeq \frac{k T}{a \eta}
$$

which is in good agreement with our results.

Acknowledgments. - It is a pleasure to thank here Drs F. Brochard, A. J. Dianoux, E. Dubois-Violette, G. Durand and F. Volino for fruitful discussions.

\section{References}

[1]] Krüger, G. J., SpIeSeCke, H. and van Steenwinkel, R., Communication à la Conférence Européenne sur les Smectiques thermotropes et leurs applications. Les Arcs, décembre 1975, to be published in J. Physique Colloq. 37 (1976) C 3.

[2] Dianoux, A. J., Volino, F., Heidemann, A. and Hervet, H., a) J. Physique Lett. 36 (1975) L-275, b) to be published.
[3] See for example : Landau, L. and LifChits, E., Mécanique des Fluides (Editions MIR, Moscou) 1971, p. 285.

[4] Helfrich, W., Phys. Rev. Lett. 23 (1969) 372.

[5] Martin, P. C., Parodi, O. and Pershan, P. S., Phys. Rev. A 6 (1972) 2401.

[6] De Gennes, P. G., The Physics of Liquid Crystals (Clarendon Press, Oxford) 1974. De Gennes notations for viscous coefficient will be used in this letter. 